\title{
Gebogene Kohlefaserstäbe für Fixateur-externe-Montagen
}

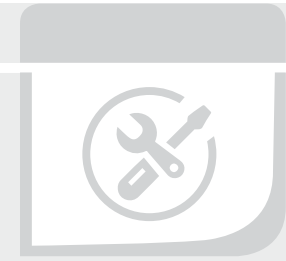

Dankward Höntzsch

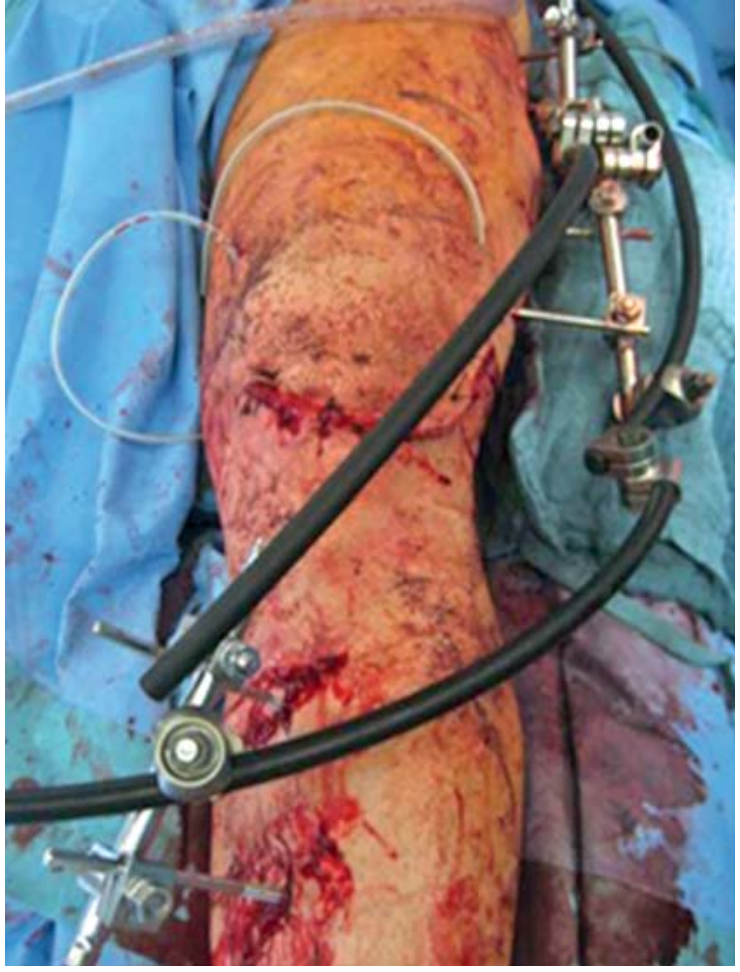

- Abb. 1 Modularer EX FIX über das Knie mit gebogenen Kohlefaserstäben I - viel einfacher.

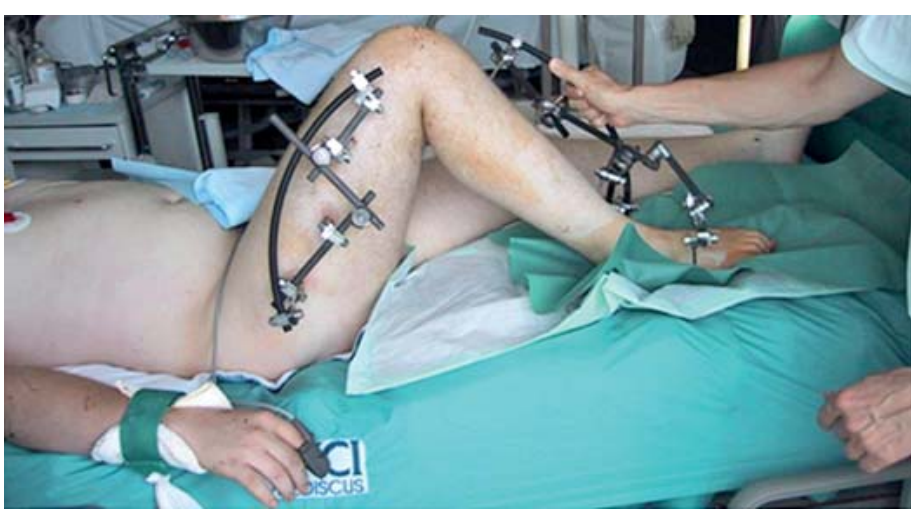

- Abb. 3 Hier als „Neutralisationsstab“ bei modularem EX FIX am Femur - es macht die EX-FIX-Anwendung einfacher.

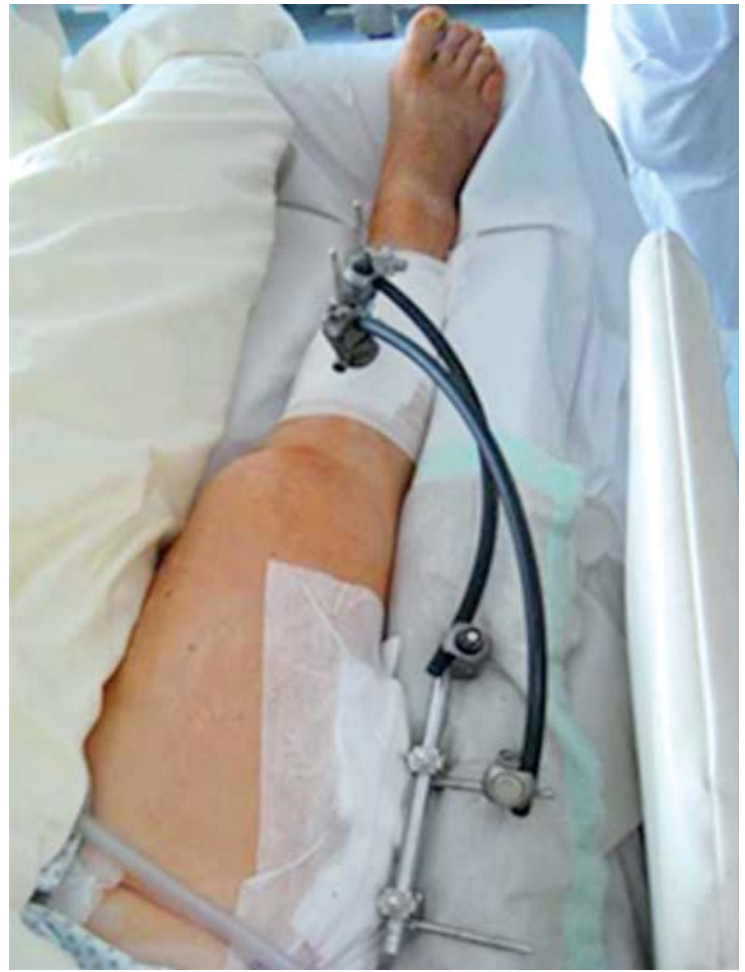

Abb. 2 Modularer EX FIX über das Knie mit gebogenen Kohlefaserstäben II - ein weiteres Beispiel von vielen anderen routinemäßigen Anwendungen an der BGU Tübingen.

Wenn es schwierig ist, komplexe Fixateur-externe-Montagen aufzubauen, können manchmal gebogene Kohlefaserstäbe helfen ( $\triangleright$ Abb. 1-5).

Damit kann man manchmal kurze oder lange Strecken „um die Ecke“ überbrücken. Besonders bewährt sich diese Montage bei der Überbrückung des Kniegelenks, so wie es von der AOTK- und EXFIX-Gruppe der AOTK empfohlen wird: vom Femur lateral oder anterior-lateral zur Tibia anterior-medial ( $\bullet$ Abb. 1 und 2 ).

Auch am Sprunggelenk und der Tibia hat es Vorteile, wenn man von den sicheren Zonen, nämlich anteriormedial an der Tibia auf Transfixationen an der distalen Tibia oder Kalkaneus überbrücken will (• Abb. 5). 


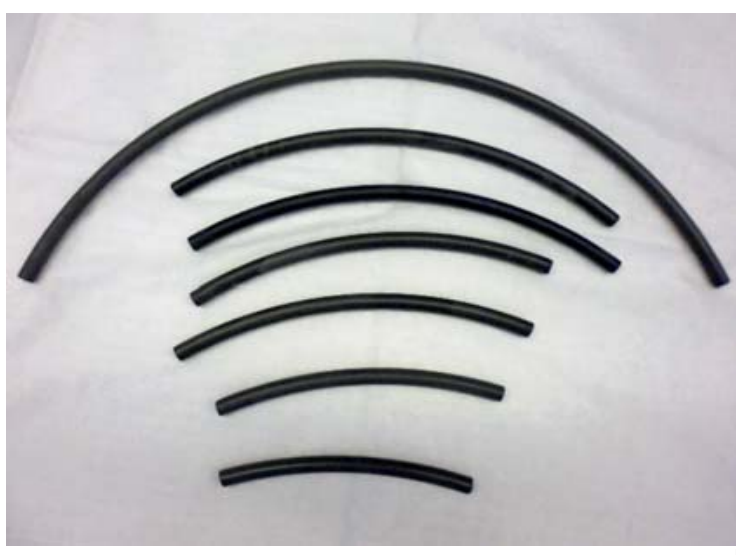

- Abb. 4 Verschieden gebogene Kohlefaserstäbe. Oben: der $180^{\circ}$-Bogen, danach verschiedene Längen. Wie die Schienen für die Modelleisenbahn.

Wie kommt man zu den gebogenen Kohlefaserstäben?

Hierzu muss man den $180^{\circ}$-Kohlefaserbogen für das Becken selbst auf die gewünschten Längen sägen. Hierzu eignet sich ein gutes und möglichst neues Metallsägeblatt. Die gesägten Enden muss man mit einer Metallfeile ein wenig nacharbeiten. So bekommt man individuelle Längen, z. B. sehr lang und sehr kurz.

Alternativ gibt es sie inzwischen auch in verschiedenen Längen bei DePuySynthes zu bestellen.

\section{Merke}

Bitte senden Sie Ihre Tipps und Tricks ein, damit dies ein lebendiger Austausch wird und wir voneinander lernen können. Bitte an: op-journal@thieme.de oder

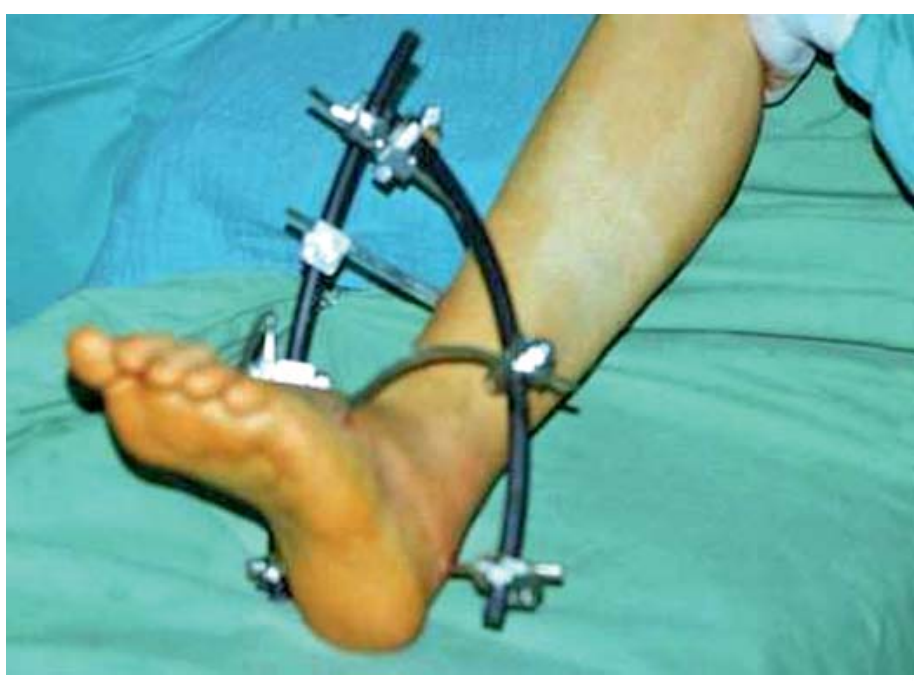

- Abb. 5 Auch am Sprunggelenk hilfreich.

Georg Thieme Verlag KG, OP-Journal, z. Hd. Frau Stickel, Rüdigerstraße 14, 70469 Stuttgart.

\section{Korrespondenzadresse}

Prof. Dr. Dankward Höntzsch

Tübingen

hoentzsch@t-online.de

\section{Bibliografie}

DOI https://doi.org/10.1055/s-0043-115012

OP-JOURNAL 2017; 33: 188-189 @ Georg Thieme Verlag KG Stuttgart · New York ISSN 0178-1715 